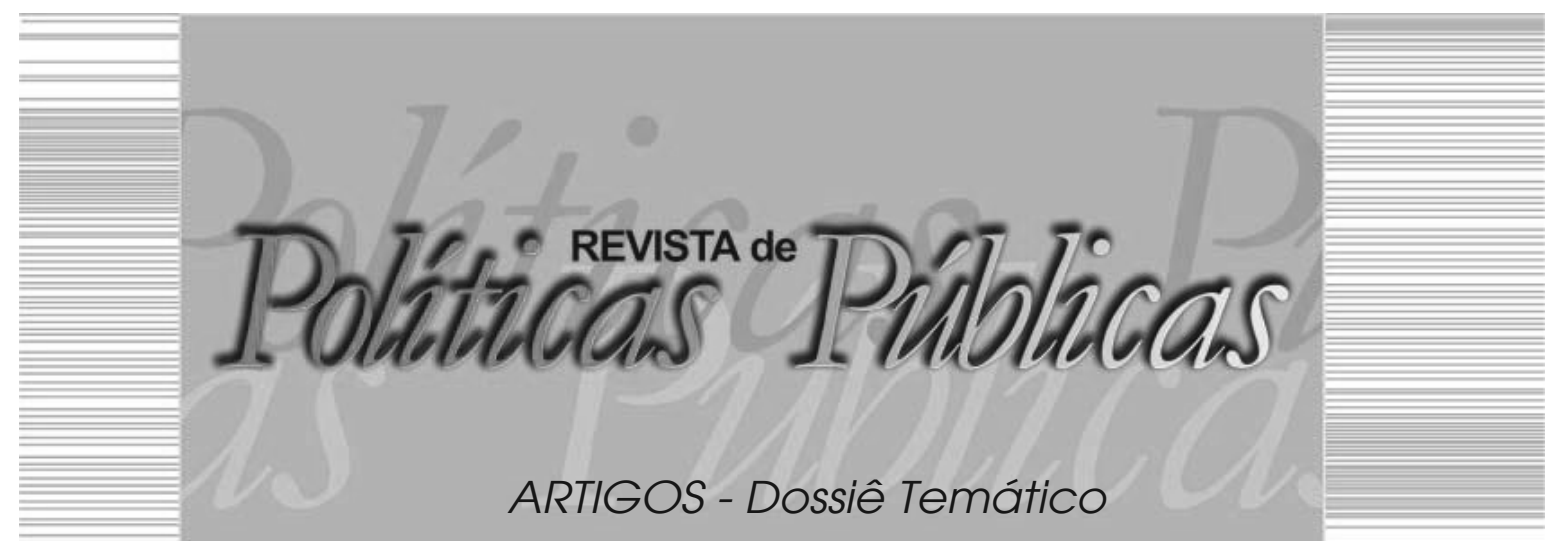

\title{
A GESTÃO EM REDES NO CONTEXTO NEOLIBERAL: o exemplo da política de assistência social brasileira
}

\author{
Talila Arrais Amorim ${ }^{1}$ \\ Prefeitura Municipal de Angical do Piauí \\ Solange Maria Teixeira ${ }^{2}$ \\ Universidade Federal do Piauí (UFPI)
}

\section{Resumo}

O presente artigo, de cunho bibliográfico, realiza uma análise crítica no tocante aos desafios do trabalho em rede como estratégia de gestão nas políticas sociais, especificamente na Política de Assistência Social frente ao contexto neoliberal. Na conjuntura marcada pela crise do capital, desmonte de direitos e retração do Estado, a gestão pública em redes vem se constituindo em uma estratégia que, de um lado, garante descentralização, relações democráticas e horizontais entre os atores e instituições e, de outro lado, a legitimidade da divisão de responsabilidades na execução da política pública com esses atores, compondo um novo modelo de gerir e de construir políticas públicas, em parcerias, um mix público/privado ou pluralismo de bem-estar social. Diante disso,

\footnotetext{
Assistente Social, Mestranda em Políticas Públicas pelo Programa de Pós-Graduação em Políticas Públicas (PPGPP) da Universidade Federal do Piaú (UFPI), Assistente Social do Centro de Referência de Assistência Social (CRAS) da Prefeitura Municipal de Angical do Piauí. E-mail: talila.arrais@gmail.com / Prefeitura Municipal de Angical do Piauí: Avenida João Siqueira Paz, S/N, Centro. CEP: 64410000

2 Assistente Social, Doutora em Políticas Públicas pela Universidade Federal do Maranhão (UFMA), Pós-Doutora em Serviço Social pela Pontifícia Universidade Católica de São Paulo (PUC-SP), Professora do Departamento de Serviço Social e do PPGPP da UFPI. E-mail: solangemteixeira@hotmail.com / Universidade Federal do Piauí - UFPI: Campus Universitário Ministro Petrônio Portella, Ininga, Teresina - Piauí. CEP: 64.049-550
} 
conclui que a estratégia de gestão em rede consagra o encolhimento do Estado e responde de maneira favorável ao capital.

Palavras-chave: Estado neoliberal, gestão em redes, Política de Assistência Social.

\title{
NETWORK MANAGEMENT IN THE NEOLIBERAL \\ CONTEXT: the example of the brazilian social assistance
}

$$
\text { policy }
$$

\begin{abstract}
This bibliographical article performs a critical analysis about the challenges of networking as a management strategy in social policies, specifically in the Social Assistance Policy about to the neoliberal context. In the conjuncture marked by the economic crisis, dismantling of rights and retraction of the State, public management in networks has become a strategy that, on the one hand, guarantees decentralization, democratic and horizontal relations between actors and institutions and, on the other hand, the legitimacy of the division of responsibilities in the execution of public policy with these actors, composing a new model of managing and building public policies, in partnerships, a public/ private mix or pluralism of social welfare. Thus, it is concluded that the network management strategy consecrates the shrinkage of the State and responds favorably to capital.

Key words: Neoliberal state, network management, Social Assistance Policy.
\end{abstract}

\section{INTRODUÇÃO}

O cenário mundial sofreu transformações ao longo do século XX, especialmente a partir dos anos de 1970 até a passagem para o século XXI, movidas pelas lutas de classe e pela ofensiva do capital contra os direitos do trabalho. A reestruturação do capital e seu processo de mundialização são mais do que uma estratégia de saída da crise, são um ataque às conquistas dos trabalhadores e seus direitos, principalmente os que colidem com as tentativas de expansão e reprodução ampliada do capital, na contemporaneidade.

A mundialização da economia proporciona um desenraizamento do capital e engendra uma sociedade capitalista global, exigindo da estrutura política, o Estado capitalista, alterações nas suas funções e nos papéis. Iamamoto (2010, p. 120) afirma que, nessa conjuntura, o "Estado tem o papel-chave de sustentar a estrutura de classes e as relações de produção". A autora revela que a mundialização da economia está interligada aos grupos industriais, que se 
A GESTÃO EM REDES NO CONTEXTO NEOLIBERAL:

o exemplo da política de assistência social brasileira

associam às instituições financeiras; a produção não se limita às peças físicas, mas também ao dinheiro, aos investimentos e fundos, ou seja, há uma produção invisível, um capital fetiche.

Com o declínio do Estado-nação, em função das desterritorializações do capital, muitos Estados perdem o poder de ditar suas políticas macroeconômicas e sociais. Segundo Castells (1998), uma das estratégias do Estado, para ter legitimidade nesse cenário, é atuar como Estado-rede, ou seja, aquele que divide poderes com outros entes governamentais, como a sociedade civil, e com os organismos internacionais. Portanto, a gestão pública deve também ser alterada - dos modelos centralizados e hierárquicos para modelos de gestão em redes de políticas públicas, de organizações e instituições, e com uma infinidade de atores que ajam sobre os mesmos objetivos, tendo o Estado, em cada órgão gestor, a coordenação do processo.

Diante disso, utilizando a tese de Mandel, Iamamoto (2010) destaca que o Estado assume a função de administrador das crises com políticas anticíclicas, um mediador entre a disputa dos dois projetos: o hegemônico neoliberal e o democrático e de luta dos trabalhadores. Assim, o Estado encarrega-se de propor ações públicas que amenizem os impactos causados pela crise capitalista e pelo ajuste estrutural dos países à nova ordem vigente, mas, diferente da época intervencionista, criando oportunidades e espaços de reprodução para o capital, inclusive no âmbito das políticas sociais. Desenvolvendo, portanto, políticas focalizadas e seletivas, cuja execução é dividida com os atores e as instituições que compõem a rede, sendo um desafio recente administrar e gerir essas redes.

Para compreender as políticas sociais, na conjuntura atual, exige-se entender a relação entre o Estado e o processo de acumulação capitalista em crise. Faleiros (2000) aponta que as políticas sociais possuem função ideológica, não podendo ser resumidas a medidas boas ou totalmente ruins, estando, então, incrustadas em um processo dialético de movimentação e de rebatimentos. $\mathrm{O}$ autor coloca que o Estado capitalista não realiza a política dos capitais individuais, "[...] ele realiza os interesses do capital." (FALEIROS, 2000, p. 70).

Assim, ao mesmo tempo em que as políticas sociais constituem terreno de efetivação de direitos sociais e espaço de luta pela cidadania, também se caracterizam como instrumento de manipulação do capitalismo mundializado. Dentro desse prisma de mundiali- 
zação e desterritorialização do capital, crise do estado de bem-estar social e redução do poder de parte significativa dos Estados-nação, percebe-se a emergência do fenômeno das redes, estratégia que, nas últimas décadas, expandiu-se de forma acelerada, tornando-se presente tanto nos discursos de gestores, como nas novas legislações, no desenho das políticas públicas, nas análises teóricas e nas conduções de práticas profissionais.

Para Teixeira (2002), tal fenômeno apresenta-se em diferentes campos, manifestando-se na existência de redes empresariais, políticas, de movimentos sociais e de apoios informais. No contexto brasileiro, quanto às políticas sociais, em especial a de Assistência Social, as ações desenvolvidas, as legislações e as orientações estão permeadas e condicionadas ao trabalho em redes.

A tese que defendemos neste artigo é de que o trabalho em rede, como estratégia de gestão nas políticas sociais, objetiva articular as ações desenvolvidas pela política, visando à eficiência, à atenção integral às necessidades dos usuários, à descentralização e à participação de forma horizontalizada. No entanto, no cenário neoliberal, esse tipo de gestão constitui campo fértil para legitimação da desresponsabilização do Estado, em que este se restringe à função de apenas regular e coordenar uma rede de serviços. O Estado encontra-se, nesse contexto de parcerias por meio das redes, desenvolvendo ações de redução de gastos sociais contando com os recursos dos parceiros, financiando aquém da necessidade de atendimento, com qualidade e quantidade da demanda, abrindo espaço para as organizações não governamentais (ONGs) e para o mercado na prestação de bem-estar social.

Nessa lógica, o presente artigo objetiva realizar uma análise crítica do modelo de gestão em redes, desvelando os interesses que estão em jogo nessa estratégia dita nova, de gerir as políticas públicas, citando o caso da Política de Assistência Social, com a rede socioassistencial, bem como os desafios e os retrocessos, que pode promover com a influência do contexto neoliberal.

\section{TENDÊNCIAS E REFLEXÕES SOBRE A GESTÃO EM REDES NO CONTEXTO DO ESTADO CAPITALISTA}

Partindo do pressuposto de que as políticas sociais possuem função ideológica e de que seu entendimento perpassa pela compreensão da relação entre Estado e sistema capitalista, a presente seção 
A GESTÃO EM REDES NO CONTEXTO NEOLIBERAL:

o exemplo da política de assistência social brasileira

se propõe refletir sobre essa relação, na tentativa de apontar alguns direcionamentos de tal política no cenário de crise, de retração do Estado, do recorte neoliberal e, como reflexo desse encadeamento, a emergência da estratégia da gestão em redes.

Para Faleiros (2000, p. 65), o Estado capitalista é "[...] uma garantia de manutenção das condições gerais de reprodução do capital e da produção, isto é, da acumulação capitalista. Ele assume os investimentos não rentáveis para o capital". A primeira saída para a crise é a econômica; nesse ponto de vista, traz consigo um conjunto de medidas que impactam, de maneira exponencial, o quadro político-administrativo.

Para Minhoto e Martins (2001, p. 83), é precisamente nesse contexto de globalização e de crise do capital "[...] que as empresas tendem a lançar mão da estrutura de rede, como parte de um conjunto de estratégias destinadas a minimizar custos e capital imobilizado, adquirir competências tecnológicas e compartilhar recursos e informações".

Castells (1999) afirma que a reestruturação do modo capitalista de produção, expressa na flexibilização e na globalização dos mercados, requisitou a aproximação do global com o local e resultou em uma nova estrutura para a sociedade. Esse quadro, marcado pelo processo de globalização da economia, também ocasionou o desmoronamento do Estado-nação.

Sob essa ótica, do grande capital ditando as regras, como sua estrutura política de comando, é que a crise do sistema capitalista, iniciada na segunda metade dos anos 1970, afeta de frente o Estado intervencionista e, dessa forma, a crise econômica e seus impactos são absorvidos por ele. Nesse enquadramento, o Estado intervencionista sofre um processo de demonização, sendo visto como burocrático, oneroso, ineficaz, ou seja, um trambolho. A demanda do capital exige que ele se retraia e repasse algumas das suas funções para o âmbito privado, para o mercado, e que mude seus modelos de gestão pública.

Castells (1999) caracteriza as novas formas organizacionais do Estado, inspiradas nos sistemas empresariais, como o O Estado-rede, uma estratégia para responder ao desafio de aumentar sua operatividade e recuperar a sua legitimidade; ao Estado caberia coordenar os diferentes níveis institucionais e as ações dos múltiplos atores 
e das instituições envolvidas na prestação de serviços. Destarte, a efetivação dessa nova atuação estatal se daria por intermédio da gestão de redes.

Nesse contexto, a intervenção em rede passou a ser vista como uma estratégia eficiente para garantir o bem-estar aos cidadãos, ao mesmo tempo em que reduziria gastos públicos e aumentaria a eficiência e a eficácia das políticas sociais, utilizando as parcerias e as articulações para compartilhar recursos, infraestruturas e técnicas. Trata-se, portanto, de uma gestão compatível com as propostas neoliberais de redução da demanda do Estado, de gastos sociais e de incentivo à busca de serviços no mercado ou nas ONGs.

Pereira (2010) destaca que é a partir da década de 1980 que se desenha um conjunto de mudanças estruturais, em escala planetária, o neoliberalismo. No Brasil, esse processo se inicia apenas na década de 1990, em função do contexto local de lutas sociais pela redemocratização do país, que culmina com a Constituição Federal (CF) de 1988, instituindo um Estado de bem-estar social no Brasil, ainda que tardiamente.

A disputa entre o projeto neoliberal e o projeto das lutas populares se acirra na década de 1990, com a escolha direta de um governo social-democrata, mas que legisla com a mão neoliberal forte, desmontando as conquistas garantidas pela CF de 1988 e adaptando as políticas sociais aos moldes do consenso neoliberal, mescladas com um falso discurso progressista. Desse modo, o Estado se retrai para ceder espaço para o capital se reproduzir amplamente, principalmente, nas políticas sociais para a população.

Sob a justificativa de melhorar a eficácia das políticas sociais frente ao contexto de crise e como alternativa à ingerência do Estado, fortalece-se a necessidade do trabalho por meio de redes e parcerias entre o Estado e a sociedade civil, o Estado e o Mercado, e entre o Estado e os outros entes governamentais (descentralização política e municipalização dos serviços) e com outros poderes estatais. Esse novo modelo de bem-estar social, que prevê a parceria entre público e privado, é conceituado por Pereira (2010) como um pluralismo de bem-estar social ${ }^{1}$. Para a autora, trata-se de uma estratégia de esvaziamento da política social como direito à cidadania.

O trabalho em rede, como estratégia de gestão nas políticas sociais, legitima a divisão de responsabilidades do Estado na oferta 
A GESTÃO EM REDES NO CONTEXTO NEOLIBERAL:

o exemplo da política de assistência social brasileira

da proteção social. Suas funções são reduzidas à de coordenador e restritas à oferta de serviços, que passam a se somar aos de outras organizações da sociedade civil, uma estratégia eficiente na contenção dos gastos públicos. A responsabilidade pela proteção social recai sobre outras esferas: família, comunidade, mercado e ONGs.

Isso posto, a estratégia de gestão por meio de redes, embora, de um lado, tenha a virtude de atender às múltiplas demandas da população de somar recursos, por outro lado, é fruto do desmonte do Estado intervencionista, bem como do desmantelamento das políticas públicas posto pelas reformas e contrarreformas neoliberais. O que se constata é a (re)privatização da questão social, considerando as vulnerabilidades como consequências de comportamentos e condutas de risco, cujo enfrentamento é atribuição da família, do próprio indivíduo, das ONGs e, de forma seletiva, do Estado.

Para melhor compreensão sobre a emergência das redes, é necessário realizar uma revisão sucinta acerca das principais definições e das tipologias em referência à categoria Rede, que segue nos subitens abaixo.

\subsection{Definições de rede}

Para Castells (1998, p. 11), “[...] uma rede, por definição, não tem centro, mas apenas nós de diferentes dimensões e relações internoidais, que são frequentemente assimétricas. Entretanto, em última instância, todos os nós são necessários para a existência da rede". O que nos remete a uma perspectiva descentralizada, em que cada ator ou instituição que integra a rede tem sua importância na construção e no desenvolvimento das ações.

Carvalho (2008, p. 2) pontua que "[...] a rede sugere uma teia de vínculos, relações e ações entre indivíduos e organizações. Elas se tecem ou se dissolvem continuamente em todos os campos. Uma rede envolve processos de circulação, articulação, participação, cooperação".

Para Teixeira (2002, p. 6), "[...] as redes de políticas são concebidas como uma forma particular de governança dos sistemas políticos modernos [...]" e "[...] apenas por meio das redes de políticas pode-se garantir a mobilização dos recursos dispersos e dar uma resposta eficaz aos problemas de políticas públicas". 
Assim sendo, frente ao terreno das políticas públicas, é importante que as leituras das redes sejam realizadas minuciosamente e de maneira crítica; é necessário levar em consideração o que não está revelado, as entrelinhas. Para Pfeifer (2009), a leitura de rede de políticas sociais é aquela que passa pela compreensão da questão social e pela indispensável mediação das políticas sociais para o acesso e a garantia de direitos sociais como respostas às suas expressões. Mas aqui se questiona: será essa a mesma leitura das políticas em redes contemporâneas?

\subsection{Tipologias das redes}

No que se refere às tipologias das redes, elas aparecem com inúmeras nomenclaturas. Aqui, são colocadas em destaque as tipologias que mais se aproximam ou auxiliam no entendimento da categoria primordial nesse esforço teórico, as políticas sociais.

Gonçalves e Guará (2010) caracterizaram as redes dividindo-as em dois grandes grupos, as redes primárias e as secundárias. As redes primárias são tecidas no cotidiano por meio do apoio mútuo, da solidariedade e de relações de afetividade, sendo formadas pelas redes espontâneas compostas, por exemplo, pela família, pela vizinhança, pelos moradores de uma rua ou de uma pequena comunidade.

No tocante às redes secundárias, os autores afirmam que, dentro delas, fazem-se presentes outros quatro tipos de redes, que são: a rede de serviços sociocomunitários, compreendidas como redes microterritoriais e uma parceira vantajosa do Estado para o enfrentamento da questão social; a movimentalista, que se caracteriza pela ação dos movimentos sociais, pela ação política e de controle social; redes setoriais públicas são as redes estatais no sentido hierárquico e verticalizado; e, por fim, as redes de serviços privados, que se caracterizam pela organização mercantil. (GONÇALVES; GUARÁ, 2010).

De acordo com Pfeifer (2009), as redes podem acontecer em três sentidos, no que se refere ao acesso e à garantia dos direitos como respostas às expressões da questão social: rede de política social, consistindo na articulação de políticas e programas governamentais e não governamentais, atuando em uma área específica da política social; redes interpolíticas sociais, constituídas pela articulação de diferentes áreas da política social; e as redes de atenção por 
grupos sociais que, por sua vez, constituem serviços de diferentes políticas sociais que atendem a grupos específicos, como redes de atenção aos idosos ou à criança, por exemplo.

Oliveira (2004, p. 8, grifos da autora) afirma, no que concerne à operacionalização das redes, que elas podem ser conjugadas em três níveis: "[...] interinstitucionais, que se articulam internamente entre os serviços, os programas e os projetos oferecidos pela mesma entidade/organização"; "[...] inter-rede, nas quais a articulação se dá entre as várias entidades/organizações, vinculados a uma determinada política social"; e as "[...] inter-redes, nas quais há articulação entre várias políticas sociais, por meio das várias entidades prestadoras de benefícios, programas e projetos".

Assim, as estratégias de gestão por meio das redes permeiam os direcionamentos das políticas sociais, especificamente o da Política de Assistência no Brasil, pós-CF/88 e pós-Lei Orgânica de Assistência Social (LOAS) (BRASIL, 1993), bem como orientam as legislações recentes: Política Nacional de Assistência Social (PNAS) (BRASIL, 2004), Sistema Único de Assistência Social (SUAS) (BRASIL, 2005) e as demais normativas que sobrelevam as ações em redes como uma diretriz essencial para a eficácia da política, uma referência de gestão e de administração descentralizada a ser seguida. (BRASIL, 1988, 1993, 2004, 2005).

\section{A POLÍTICA DE ASSISTÊNCIA SOCIAL NO \\ CONTEXTO NEOLIBERAL: a ação em rede como estratégia de gestão}

A Assistência Social brasileira constituída como política social pós-CF de 1988, integrante do tripé: Previdência Social, Saúde e Assistência Social, engenhou-se permeada pelos impactos ocasionados pela mundialização e crise do capital, colapso do Welfare State (cabe ressaltar que este não se realizou, de fato, em solo brasileiro), bem como da retração do Estado aos moldes neoliberais.

Com isso, o limitado Estado Social brasileiro retrai-se ainda mais, instaurando-se um quadro de divisão de responsabilidades com a sociedade, não apenas no financiamento do sistema pelo fundo público, mas também na execução da política em diferentes planos. Ao mesmo tempo em que cresce na organização do sistema, regulando e distribuindo responsabilidades para outros entes governamentais e sociedade civil, e coordenando os serviços por intermédio de unida- 
des públicas - como os Centros de Referência de Assistência Social (CRAS) e os Centros Especializados em Assistência Social (CREAS) -, como porta de entrada para o acesso à rede socioassistencial, instaura um novo modo de fazer política pública, com as parcerias.

Dentre as propostas neoliberais, destacam-se as de cortar gastos públicos, leia-se gastos sociais, e a de redução do papel do Estado e de suas funções no campo econômico e social, comprometendo a alocação de recursos no âmbito das políticas sociais e provocando um processo de desmonte nos incipientes aparatos dos sistemas de proteção social latino-americanos. Como destacam Netto e Braz (2006), Estado mínimo para o trabalho e máximo para o capital.

Nesse contexto, acirram-se os projetos em disputa na política de Assistência Social, o familista e o projeto protetivo, que se entrelaçam no desenho da política nos anos 2000, nas várias legislações. Entretanto, a contradição que perpassa essa política é a mesma que está imbricada em qualquer política pública na ordem capitalista, por atender interesses antagônicos. Diante desse prisma, o desenvolvimento das políticas sociais não pode ser compreendido como um processo linear, de conotação exclusivamente positiva ou negativa. Pelo contrário, ele se mostra simultaneamente positivo e negativo, porque pode beneficiar interesses antagônicos, conforme a direção das disputas de poder e a correlação de forças prevalecentes. (PEREIRA, 2009).

A partir da promulgação da Constituição de 1988 , que tem como um dos seus princípios o fortalecimento da cidadania, foi possível garantir legalmente um aparato de proteção social. Dessa maneira, a Política de Assistência Social materializa-se na CF de 1988 por meio do sistema de Seguridade Social. (BRASIL, 1988). No que concerne à assistência social, a LOAS, promulgada apenas em 1993, é alvo de vetos e, posteriormente, de desmonte no governo Fernando Henrique Cardoso (FHC).

Para Draibe (1993, p. 93), durante os primeiros anos da década de 1990, a agenda neoliberal modifica-se, e tais "[...] modificações se relacionam com os desafios na modernização e na melhoria e competitividade sistêmica das economias, na busca da integração internacional". Mas, com a reforma do Estado, no governo FHC, inicia-se a adesão aos modelos de gestão descentralizados, gerenciais, do Estado em rede. O primeiro passo é incluir as organizações não governamentais na agenda pública, regulamentar e legitimar suas 
A GESTÃO EM REDES NO CONTEXTO NEOLIBERAL:

o exemplo da política de assistência social brasileira

ações como de cunho público por exercerem atividades não lucrativas e de cunho social.

Nessa lógica, o Estado deve garantir apenas o mínimo, ficando a cargo do indivíduo e sua família a superação de suas vulnerabilidades; a mão do Estado se direciona apenas aos mais pobres. Assim, as políticas sociais se tornam cada vez mais focalizadas e seletivas, em especial a política de Assistência Social.

Destarte, diante dos retrocessos asseverados na década de 1990, notadamente nas gestões Fernando Collor/Itamar Franco e FHC, do recuo dos movimentos sociais, da disseminação da ideologia neoliberal e, posteriormente, nos governos Luís Inácio Lula da Silva e Dilma Rousseff, com a lógica neodesenvolvimentista, que não rompe com as tendências de focalização nos mais pobres, assim como nos programas de transferência de renda com condicionalidades, e com o desenvolvimento econômico nos moldes da acumulação flexível, ampliam-se as legislações da assistência social, com avanços nas proteções sociais a serem asseguradas, como a PNAS 2004 e o SUAS 2005, 2012. (BRASIL, 2004, 2005, 2012).

Montaño (2014), desvendando o que denomina de o canto da sereia, que mascara, encobrindo as influências neoliberais, aponta as novas tendências da Política de Assistência Social, que se apresentam mediante a atuação em redes, regulação da parceria público/ privado, chamamento à participação da família, incentivo ao empreendedorismo, economia solidária e o processo de refilantropização.

A noção de rede é explícita no desenho da política; as organizações não governamentais atuam como parte integrante da rede socioassistencial, compondo com as organizações estatais e os diversos entes estatais, o Sistema Único de Assistência Social, logo, uma participação ativa, central e não apenas complementar.

Montaño (2014) aponta que os governos conceituados por ele como pós-neoliberais ${ }^{2}$, governo de Luís Inácio Lula da Silva e Dilma Rousseff, apenas dão continuidade à lógica existente, repondo a manutenção da pobreza, administrada e controlada pelos programas de transferência de renda e de centralidade na família. Apesar do crescimento das políticas sociais nesse contexto, as políticas compensatórias tiveram predominância em detrimento das políticas universais e redistributivistas. 
Contudo, é durante a gestão do governo do Partido dos Trabalhadores (PT) que acontece a promulgação da Política Nacional de Assistência Social/2004, por meio da Resolução $\mathrm{n}^{\circ}$ 145, de 15 de outubro de 2004, que "[...] expressa a materialidade do conteúdo da assistência social como um pilar do Sistema de Proteção Social Brasileiro no âmbito da Seguridade Social" (BRASIL, 2004, p. 11); e o tão esperado SUAS de 2005, surge como promessa na organização efetiva das ações da política. (BRASIL, 2005).

No entanto, para Montaño (2014), os presidentes petistas aprofundaram seus laços com o capital extrativista, conseguindo conservar o apoio das massas mediante os programas de repasse de renda com condicionalidades, focalizando na pobreza e não nas relações que a produzem, e com o desenvolvimento econômico na perspectiva da ofensiva neoliberal.

No que se refere ao governo atual, do presidente Michel Temer (governo constituído por via de um golpe político), o que se constata é um desmonte de direitos e um retrocesso pós-constituição, considerando o ajuste fiscal proposto, em moldes neoliberais ortodoxos. O plano temerário A Travessia Social uma ponte para o futuro. (FUNDAÇÃO ULYSSES GUIMARÃES, 2016) propõe o congelamento do orçamento das políticas sociais por meio das Propostas de Emendas Constitucionais (PECs). Os movimentos sociais e a sociedade assistem, atônitos, à desconstrução da democracia e dos direitos sociais garantidos constitucionalmente.

O plano proposto por Michel Temer nada mais é do que uma ponte para o retrocesso e, por que não dizer, ponte para um abismo social. Concentra-se em três grandes eixos: desregulação do Estado, seletividade e focalização das políticas sociais e reforço da parceria público/privado.

Os ataques às políticas sociais brasileiras universalistas e a focalização nos mais pobres podem ser constatadas nos seguintes trechos extraídos do Plano:

\footnotetext{
Em qualquer horizonte razoável, o Estado terá que renunciar a funções de que hoje se ocupa, e terá mesmo que amputar partes de sua arquitetura. Sem fazer isto, o crescimento econômico duradouro não será possível.
}

$[\ldots]$ 
A GESTÃO EM REDES NO CONTEXTO NEOLIBERAL:
o exemplo da política de assistência social brasileira

Tratar a população brasileira como um todo, para os fins de políticas públicas, é um erro frequente. (FUNDAÇÃO ULYSSES GUIMARÃES, 2016, p. 5, grifo nosso).

O governo estará empenhado na criação e na melhoria dos bens públicos à disposição da população, em especial das populações mais pobres, mas não será mais seu provedor direto (FUNDAÇÃO ULYSSES GUIMARÃES, 2016, p. 8, grifo nosso).

De acordo com o plano, o Estado terá que "[...] amputar partes de sua arquitetura.", criada pela CF/1988; dessa forma, esse Estado capenga necessitará cada vez mais estabelecer parcerias, ou seja, a gestão em rede, vista atualmente como um tipo de panaceia para todos os males, será ainda mais fortalecida como diretriz norteadora da política social. (FUNDAÇÃO ULYSSES GUIMARÃES, 2016, p. 5).

\subsection{A gestão em redes na política nacional de assistência social:} a rede socioassistencial

A ação em rede se consolida, de fato, na assistência social brasileira com a promulgação da PNAS 2004, que indica que trabalhar em rede possibilita a superação de ações fragmentadas; "[...] há a necessidade de se romper com velhos paradigmas, em que as práticas se construíram historicamente pautadas na fragmentação e segmentação.” (BRASIL, 2005, p. 32).

Silva e Teixeira (2016) destacam três modalidades de atuação em rede nas ações socioassistenciais da PNAS/2004: a articulação entre Estado e sociedade civil, estabelecida no art. $1^{\circ}$ da LOAS, que prevê que a assistência social deverá ser oferecida por meio de "[...] um conjunto integrado de ações de iniciativa pública e da sociedade." (BRASIL, 2012, p. 1); a descentralização político-administrativa para os Estados, o Distrito Federal e os municípios, sendo prevista pela PNAS 2004, objetivando uma intervenção mais efetiva e evitando paralelismo de ações; e a rede intersetorial, entre políticas setoriais. (SILVA; TEIXEIRA, 2016, p. 143).

A rede socioassistencial é a materialização da Política de Assistência Social, definida como:

[...] um conjunto integrado de ações de iniciativa privada e da sociedade que ofertam e operam benefícios, serviços, programas e projetos, o que supõe a articulação entre todas estas unidades de 
provisão de proteção social, sob hierarquia básica e especial e ainda por níveis de complexidade (BRASIL, 2005, p. 40).

Tal rede é composta diretamente por organizações governamentais, pelos órgãos gestores municipais e pelas organizações e entidades de assistência social. De acordo com a NOB/SUAS (2005, 2012), a dinâmica da rede socioassistencial em defesa dos direitos de cidadania considera o cidadão e a família não como objeto de intervenção, mas como sujeito protagonista da rede de ações e serviços; abre espaços e oportunidades para o exercício da cidadania ativa no campo social, atuando sobre o princípio da reciprocidade; sustenta a auto-organização do cidadão e da família no desenvolvimento da função pública, logo, verifica-se que há um amplo processo de parcerias explícitas. (BRASIL, 2005, 2012).

Essa rede organiza-se a partir dos seguintes parâmetros: a oferta integrada, o caráter público de corresponsabilidade e de complementaridade das ações entre ações governamentais e não governamentais, a hierarquização entre a básica e a especial, a porta de entrada unificada de serviços, a oferta capilar e o caráter contínuo e sistemático.

A desigualdade e a pobreza, inerentes à sociedade capitalista contemporânea, engendram diferentes modalidades de desproteção social que exigem atenção estatal diferenciadas para o seu enfrentamento. Entretanto, essa responsabilidade é dividida com a sociedade civil num processo que se denomina de refilantropização, dada a importância dessas parcerias, que também são exigidas das famílias beneficiárias.

A rede socioassistencial deve ser articulada por proteções, entre seus tipos, mediante seus serviços. A proteção básica se propõe "[...] prevenir situações de risco social, por meio do desenvolvimento de potencialidades e aquisições do fortalecimento de vínculos familiares e comunitários." (BRASIL, 2005, p. 33), atuando por meio dos CRAS. A proteção social especializada tem como instituição de suporte os CREAS e, como objetivo, a reconstrução de vínculos familiares. Essas proteções são compostas de inúmeros serviços, alguns de execução exclusiva do Estado e outros que podem ser executados por toda a rede.

A gestão em rede também administra as articulações entre as proteções e as organizações de assistência social; assim, têm-se diferentes atores e instituições que se unem por um objetivo comum: 
A GESTÃO EM REDES NO CONTEXTO NEOLIBERAL:

o exemplo da política de assistência social brasileira

a materialização da política. O Estado, mediante o órgão gestor municipal, teria a função de coordenar a rede e capacitá-la, sendo os CRAS a porta de entrada no sistema.

Nas políticas públicas, em especial na PNAS/2004, a gestão em redes apoia-se numa série de possíveis vantagens, que vêm se transformando num apelo a essas iniciativas. Segundo Teixeira (2002), suas características são: maior mobilização de recursos e diversidade de opiniões devido à pluralidade de atores; definição de prioridades realizadas de forma mais democrática por causa da capilaridade presente nas redes; criação de uma presença pública sem que haja uma estrutura burocrática; desenvolvimento de uma gestão adaptativa devido à flexibilidade da dinâmica das redes. Assim, os objetivos e as estratégias são frutos de consensos resultantes de processos de negociação.

Entretanto, há inúmeros desafios, dentre eles, Teixeira (2002) destaca: as dificuldades em lidar com as contas públicas em relação ao uso dos recursos públicos, já que envolvem numerosos participantes governamentais e privados; a lentidão no processo de geração de consensos e negociação; as responsabilidades são muito diluídas; há uma ausência de critérios explícitos e universais para participação na rede, podendo provocar a marginalização de determinados atores, até mesmo regiões, e deixar a política apenas nas mãos de uma elite, com a qual se mantêm convênios, que vencem os editais, que concentram maior número de serviços prestados. Desse modo, percebe-se que há relações de poderes e de influência diferenciada entre as organizações da sociedade civil componentes da rede socioassistencial.

Ainda conforme Teixeira (2002, p. 19), na gestão em redes, "[...] o gestor público deixa de ser um cumpridor de planos para ser um negociador, capaz de incentivar o diálogo, coletivizar ideias, formular alternativas e articular ações conjuntas". Na rede sociassistencial, atingir esses objetivos é um grande desafio, considerando a histórica cultura assistencialista, religiosa e filantrópica das organizações de assistência social, assim como a falta de tecnicidade e conhecimento das legislações da política dos gestores municipais. O caciquismo ainda é forte em muitos municípios de pequeno porte e os conselhos de políticas públicas apresentam-se como funcionais à lógica da gestão. 


\section{CONCLUSÃO}

Diante do exposto no presente artigo, que teve como propósito refletir acerca da Política de Assistência Social e da ação em redes como estratégia de gestão no contexto neoliberal, conclui-se que o movimento em torno da expectativa de gestão descentralizada, democrática e de relações horizontais tende a se ampliar, considerando o ajuste fiscal neoliberal e as propostas de redução dos gastos públicos. Assiste-se a recuos da lógica do Estado de bem-estar social e ao avanço de um novo modelo de fazer política social em parcerias com o setor privado. Esse modelo impõe novas formas de gestão pública: a gestão em redes.

A gestão em redes de políticas públicas ou no interior de uma política, semelhante à estratégia do capital ao descentralizar-se, terceirizar e tornar suas relações com outras empresas mais flexíveis e de troca, tem os mesmos objetivos, reduzir gastos ou custos. Dessa forma, não se trata da prevalência da lógica da solidariedade que rege as articulações entre inúmeras organizações de assistência social, mas a de diminuir o tamanho do Estado, reduzir suas demandas e repassá-las para a sociedade civil e para a família ou mercado, processo esse de desregulamentação do Estado.

A gestão por meio de redes tem um forte apelo, o da democratização, da descentralização, das relações horizontalizadas, policêntricas, sem mando ou comando hierárquico, típicas das gestões gerenciais, que lidam com parceiros, corresponsáveis pelo bem-estar social. Na verdade, um canto de sereia que impede a visão para além da aparência.

Trata-se, sem dúvida, de um modelo de gestão que se realiza nas empresas e difunde-se para o Estado, desmantelando a política social como direito de cidadania, mercantilizando ou refilantropizando as formas de enfrentamento da questão social; uma (re)privatização do seu enfrentamento, em oposição latente ao Estado intervencionista. Destarte, a descentralização é do Estado para a sociedade civil, uma sociedade atuante e solidária que protege diretamente seus membros mais pobres, típica do pensamento neoliberal. A gestão e o trabalho em rede respondem de maneira favorável ao capital.

Portanto, o grande desafio é colocar pitadas de insurgências nesse processo antinômico, resistindo ao conformismo, para que as políticas sociais, como arena de disputa entre os projetos societários, 
acarretem, como resultado dessa controvérsia, mudanças no reconhecimento e na garantia da cidadania e, assim, sejam verdadeiras pontes concretas que possibilitem a ascensão de um novo projeto social coletivo e de uma sociedade igualitária.

\section{REFERÊNCIAS}

BRASIL. Constituição (1988). Constituição da República Federativa do Brasil. Brasília, DF: Senado Federal: Centro Gráfico, 1988. 292 p.

. Ministério da Previdência e Assistência Social. Secretaria de $\overline{\text { Estado de Assistência social. Lei no }}{ }^{\circ} .742$, de 7 de dezembro de 1993. Lei Orgânica da Assistência Social. Dispõe sobre a organização da Assistência Social e dá outras providências. Diário Oficial da União, Brasília, DF, 1993.

Ministério do Desenvolvimento Social e Combate à Fome. Norma Operacional Básica da Assistência Social (NOB\SUAS). Brasília, DF, 2005.

. Norma Operacional Básica da Assistência Social (NOB\SUAS). Brasília, DF, 2012.

Secretaria Nacional de Assistência Social. Política Nacional de Assistência Social (PNAS). Brasília, DF, 2004.

CARVALHO, M. do C. B. de. A ação em rede na implementação de políticas e programas sociais públicos, 2008. Disponível em: <www. redesabara.org.br>. Acesso em: 10 ago. 2015.

CASTELLS, M. A era da informação: economia, sociedade e cultura: a sociedade em rede. São Paulo: Paz e Terra, 1999.

. Hacia el estado red? Globalización econômica e instituciones políticas en la era de la información. In: SEMINÁRIO INTERNACIONAL SOCIEDADE E REFORMA DO ESTADO, 1998, Brasília, DF. Anais ... Brasília, DF: Mare online, 1998. p. 1-16.

DRAIBE, S. M. As políticas sociais e o neoliberalismo: reflexões suscitadas pelas experiências latino-americanas. Revista USP, São Paulo, v. 1, n. 17, p. 86-101, jan. 1993.

FALEIROS, V. de P. A política social do Estado Capitalista. São Paulo: Cortez, 2000.

FUNDAÇÃO ULYSSES GUIMARÃES. Travessia Social: uma ponte para o futuro. [S. 1.], 2016. Disponível em: $<$ http://veja.abril.com. $\mathrm{br} /$ complemento/pdf/TRAVESSIA\%20SOCIAL\%20-\%20PMDB_ 
LIVRETO_PNTE_PARA_O_FUTURO.pdf >. Acesso em: 09 nov. 2016.

GONÇALVES, A; GUARÁ, I. M. e. R. Redes de proteção social na comunidade. In: GUARÁ, I. M. e. R. (Orgs.). Redes de Proteção Social. São Paulo: Associação Fazendo História; NECA - Associação dos Pesquisadores de Núcleos de Estudos e Pesquisas sobre a Criança e o Adolescente, 2010.

IAMAMOTO, M. Serviço Social em tempos de capital fetiche. São Paulo: Cortez, 2010.

MINHOTO, L. D.; MARTINS, C. E. As redes e o desenvolvimento social. Cadernos Fundap, São Paulo, v. 1, n. 22, p. 81-101, jun. 2001. Disponível em: <www.abdl.org.br/.../287/as-redes-e-odesenvolvimento-social.pdf>. Acesso em: 11 ago. 2016.

MONTAÑO. C. O Canto da Sereia: crítica à ideologia aos projetos do “Terceiro Setor". São Paulo: Cortez, 2014.

OLIVEIRA, M. de. Acessando direitos sociais: redes municipais de políticas sociais - espaço de articulação entre as políticas sociais públicas. Textos e Contextos, Porto Alegre, v. 1, n. 3, p. 1-13, dez. 2004.

PAULO NETTO, J.; BRAZ, M. Economia política: uma introdução crítica. São Paulo: Cortez, 2006.

PEREIRA, P. A. P. Mudanças estruturais, política social e papel da família: crítica ao pluralismo de bem-estar. In: SALES, M. A.; MATOS, M. C. de; LEAL, M. C. (Orgs.). Política social, família e juventude: uma questão de direitos. 6. ed. São Paulo: Cortez, 2010. . Política social: temas e questões. São Paulo: Cortez, 2009.

PFEIFER, M. Notas Acerca das Redes de Políticas Sociais. In: SIMPÓSIO SOBRE FAMÍLIAS: Políticas de Atendimento, 1., 2009, Tubarão. Anais.... Tubarão: UNISUL, 2009.

SILVA, K. R. A. da; TEIXEIRA, S. M. Rede socioassistencial: desafios da gestão de redes na Política de Assistência Social. In: TEIXEIRA, S. M. (Org.). Política de Assistência Social e Temas Correlatos. Campinas, SP: Papel Social, 2016. p. 131-151.

TEIXEIRA, S. M. F. O desafio da gestão das redes de políticas. In: VII CONGRESO INTERNACIONAL DEL CLAD SOBRE LA REFORMA DEL ESTADO Y DE LA ADMINISTRACIÓN PÚBLICA, 7., 2002, Lisboa. Anais eletrônicos... Lisboa: CLAD, 


\section{A GESTÃO EM REDES NO CONTEXTO NEOLIBERAL: \\ o exemplo da política de assistência social brasileira}

2002. p. 1-24. Disponível em: <http://unpan1.un.org/intradoc/groups/ public/documents/CLAD/clad0043204.pdf>. Acesso em: 05 out. 2016.

\section{NOTAS}

Caracterizado pela "[...] ação compartilhada do Estado, do mercado (incluindo as empresas) e da sociedade (organizações voluntárias, sem fins lucrativos, a família ou rede de parentesco) na provisão de bens e serviços que atendam as necessidades humanas básicas." (PEREIRA, 2009, p. 199).

2 A concepção é de que o perecimento do modelo neoliberal não foi sucedido por um modelo alternativo que pudesse substituí-lo em escala global. 
